\title{
PREVALENCE OF HUMAN PAPILLOMAVIRUS GENOTYPES IN LOW AND HIGH GRADE SQUAMOUS INTRAEPITHELIAL LESIONS AT CERVICAL TISSUE
}

\author{
Rizki Eko Prasetyo ${ }^{1}$, Gondo Mastutik ${ }^{2}$, Sjahjenny Mustokoweni ${ }^{2}$ \\ ${ }^{1}$ Master Program of Basic Medical Science, Faculty of Medicine, Universitas Airlangga, ${ }^{2}$ Department of Anatomic \\ Pathology, Faculty of Medicine, Universitas Airlangga
}

\begin{abstract}
ABSTRAK
Infeksi HPV diketahui sebagai penyebab kanker serviks. Penelitian ini bertujuan untuk mengidentifikasi genotipe HPV pada lesi pre kanker serviks dari low grade squamous intraepithelial lesion (LSIL) dan high grade squamous intraepithelial lesion (HSIL). Penelitian ini merupakan penelitian eksplorasi menggunakan blok parafin dari lesi prakanker serviks di RSUD Dr Soetomo Surabaya. DNA diektraksi dari blok parafin dan dihibridisasi menggunakan Ampliquality HPV Type Express kit (AB ANALITICA) dengan teknik reverse line blot. Hasil penelitian ini menunjukan bahwa terdapat varian genotipe HPV pada LSIL yaitu HPVI6 (8/15), HPV18 (3/15), HPV52 (1/15), HPV6+31 (1/15), HPV6+18 (1/15), HPV72+68 (1/15), dan HSIL yaitu HPV16 (4/10), HPV18 (2/10), HPV59 (1/10), HPV6+45 (1/10), HPV61+26 (1/10), HPV16+31 (1/10). Karakteristik infeksi pada LSIL yaitu infeksi tunggal HPV high-risk (hr), infeksi multiple HPV low-risk (lr)+hr, dan HSIL yaitu infeksi tunggal HPV hr, infeksi multiple HPVhr+hr, HPVlr+hr. Sebagai simpulan, prevalensi HPV pada lesi prakanker serviks yaitu infeksi tunggal oleh HPV16 (48\%), HPV18 (20\%), HPV52 (4\%), HPV59 (4\%), dan infeksi mutiple oleh HPV6+31, HPV6+18, HPV6+45, HPV16+31, HPV61+26, HPV72+68 yaitu 4\%. (FMI 2017;53:258-263)
\end{abstract}

Kata kunci: Genotipe HPV; LSIL; HSIL

\begin{abstract}
HPV infection is known to cause cervical cancer. This study aimed to identify the variant of HPV genotypes of cervical precancerous lesions from low grade squamous intraepithelial lesion (LSIL) and high grade squamous intraepithelial lesion (HSIL). This was an explorative study using formalin fix paraffin embedded (FFPE) from cervical precancerous lesions at Dr. Soetomo Hospital, Surabaya. DNA was extracted from FFPE and hybridized for HPV genotyping using Ampliquality HPV Type Express kit (AB ANALITICA) by reverse line blot techniques. The results showed that there were variants of HPV genotype in LSIL. The variants were HPV16 (8/15), HPV18 (3/15), HPV52 (1/15), HPV6+31 (1/15), HPV6+18 (1/15), and HPV72+68 (1/15), and in HSIL which were HPV16 (4/10), HPV18 (2/10), HPV59 (1/10), HPV6+45 (1/10), HPV61+26 (1/10), and HPV16+31 (1/10). The characteristics of infection in LSIL were single infection of high-risk (hr) HPV and multiple infection of low-risk (lr) $+h r$ HPV, and in HSIL were single infection of HPVhr, multiple infection of HPVhr+hr and HPVlr+hr. In conclusion, HPV prevalence in cervical precancerous lesions is single infection by HPV16 (48\%), HPV18 (20\%), HPV52 (4\%), HPV59 (4\%), and multiple infection by HPV6+31, HPV6+18, HPV6+45, HPV16+31, HPV61+26, HPV72+68 is 4\%. (FMI 2017;53:258-263)
\end{abstract}

Keywords: HPV genotypes; LSIL; HSIL

Correspondence: Gondo Mastutik, Department of Anatomic Pathology, Faculty of Medicine, Universitas Airlangga, J1. Prof Dr Moestopo 47, Surabaya 60131. Phone: 62-31-5020251, ext 151. Email: gondomastutik@ gmail.com

\section{INTRODUCTION}

Various variants of HPV genotype in precancerous lesions were found in West Java and Bali. Schellekens (2004) in Jakarta found a combination of HPV genotypes involved in single infections and multiple infections with HPV, which is the dominant high-risk HPV 16 followed by high-risk HPV 18 and 52. Vet et al (2008) obtained HPV genotype variants of precancerous lesions in Jakarta which were predominantly high-risk HPV 52 followed by high-risk HPV 16 and 39, low-risk HPV 70 and HPV genotype 6. The HPV variants of precancerous lesions in Tasikmalaya were mostly the high-risk HPV 18 followed by high-risk HPV 52, 16, and 39. The low-risk HPV genotype of HPV 70 variants in precancerous lesions in Bali was predominantly high-risk HPV 52 followed by high-risk HPV 16, 18, 51 and 53. A study in Bandung by Sahiratmadja (2014) detect-ed high-risk HPV involvement in precancerous lesions, mostly the high-risk HPV 16 followed by high-risk HPV 18, 52, 45 and 51 in single infections and multiple infections. The study of HPV genotypes in cervical cancer patients in Dr. Hasan Sadikin Hospital, Bandung showed the results of a single infection of high-risk HPV 16, 18, and 35, and the combined high-risk HPV infection with high-risk HPV 16, 18, 33, 45, 51, and 52 (Tobing et al 2014). Previous studies have identified the 
variants of HPV genotypes in Dr. Soetomo Hospital, Surabaya.

The oncoproteins of E6 and E7 HPV have role in the occurrence of malignant transformation. Rahmawati et al (2014) suggested that there is a correlation, but not significant, between E6 and E7 oncoprotein expression in precancerous lesions. E6 and E7 oncoproteins have potential as a marker of malignancy. The effort to address cervical cancer up to now is the use of vaccine as a preventive measure of HPV infection. Food and Drug Administration (FDA) approved the bivalent and quadrivalent vaccine. Bivalent vaccine can prevent infection with high-risk HPV 16 and 18. The quadrivalent vaccine can prevent infection in addition to high-risk HPV 16 and 18 and low-risk HPV 6 and 11 (Markowitz et al 2016). The immunization of high-risk HPV 16 L1 VLP was expected to protect high-risk HPV 16 infection but not against other HPV genotypes. Vaccine generation of Virus-Like Particles (VLP) currently only contains high-risk HPV 16 and 18. HPV 16 is the cause of $45.3 \%$ of precancerous lesion cases and HPV 18 cause $6.9 \%$ of cases of precancerous lesions in the world (Smith et al 2007). Protection with target of $70 \%$ requires vaccines that induce significant cross protection against other oncogenic HPV. This kind of cross protection for the mechanism is not clear, while the experimental evidence suggests that the antibodies produced by the VLP should be that of specific type (Stanley et al 2006). Nonavalent vaccine which has been currently developed is expected to protect the nine genotypes of HPV, namely low-risk HPV 6 and 11, high-risk HPV $16,18,31,33,45,52$, and 58 as well as to prevent 80 $90 \%$ of cervical cancer (Markowitz et al 2016). Because of the prevalence of high-risk HPV, nonavalent vaccine needs to be adapted to be used in different countries. The variants of HPV genotypes in Dr. Soetomo Hospital Surabaya are needed to be examined to assess the effectiveness of vaccine on the prevention of HPV infection in Dr. Soetomo Hospital, Surabaya.

WHO (2014) obtains data on 490,000 women with cervical cancer in the world each year. $80 \%$ are in developing countries, one of which is Indonesia. New cases appear every minute, and in every two minutes, there is one person dying from cervical cancer. The Ministry of Health by the Hospital Information System (2014) noted that the most common cancer that attack the population of Indonesia is cervical cancer. Forty to forty-five new cases of about 20-25 people die from cervical cancer each day, which means that every month Indonesia losts 600-750 women from cervical cancer. Cervical cancer mortality rate in Indonesia is high and largely due to the delay in diagnosis (Sherris et al 2009).
Studies about variants of HPV genotypes in a few places in the world have been done. Smith et al (2007) found the prevalence of five major genotypes of HPV in precancerous lesions in Europe which predominantly was HPV 16, then followed by HPV 31, 33, 18, and 58. In Africa, it was HPV 16, followed by HPV 33, 31, 18, and 52. In North America, it was HPV 16 followed by HPV 18, 31, 35, and 58, while in Central and South America it was HPV 16, 58, 18, 31, and 33. Whereas, the prevalence of HPV in the world are HPV 16 $(45.3 \%), 31(8,6 \%), 33(7.3 \%), 58(7.0 \%)$, and 18 (6.9\%). Vet et al (2008) obtained HPV genotype variants in Jakarta, namely high-risk HPV 52 (14.8\%), $16(10.7 \%)$, and $39(9 \%)$, low-risk HPV 70 (6.6\%), and $6(6.6 \%)$. Variants of HPV genotypes in Tasikmalaya were high-risk HPV 18 (17.3\%), 52 (16\%), 16 (12.3\%), and $39(9.9 \%)$, and low-risk HPV genotype HPV 70. Variants of HPV in Bali were high-risk HPV 52 (18\%), $16(15 \%), 18(12 \%), 51(8 \%)$ and $53(7 \%)$. A study in Bandung by Sahiratmadja (2014) obtained high-risk HPV 16 (100\%), 18 (56\%), 52 (52\%), 45 (48\%), and 51 $(8 \%)$ on a single infection or coinfection. Therefore, a study to determine the genotypes of HPV which cause precancerous lesions in Dr. Soetomo Hospital, Surabaya needs to be done.

\section{MATERIALS AND METHODS}

This was an observational study with exploratory design. The population was cervical tissue with LSIL and HSIL in the preparation of paraffin blocks (FFPE) of sexually active female patients who had been examined in Dr. Soetomo Hospital Surabaya. The sample selection of nonprobability paraffin blocks used sequential sampling technique, assisted by experts of pathology with time restriction from January to December 2014.

This study was conducted at the Institute of Tropical Diseases of Hepatitis Laboratory, Universitas Airlangga, for 8 months from December 2015 to August 2016 after getting approval from the Research Ethical Committee, Dr. Soetomo Hospital, Surabaya. The initial step was LSIL and HSIL sample preparation in paraffin blocks (FFPE) was deparaffinized using appropriate protocol with nucleospin kit, then we obtained suitable DNA extraction kit QIAGEN protocols. Samples were in the form of DNA extraction in the PCR protocol using Ampliquality HPV-Type Express to get a PCR product, then the PCR product was used for HPV genotype examination by the method of Single Step PCR and Reverse Line Blot capable of identifying 40 HPV genotypes (HPV 6, 11, 16, 18 , 26, 31, 33, 35, 39, 40, 42, 43, 44, 45, 51, 52, 53, 54, 55, 56, 58, 59, 61, 62, 
$64,66,67,68 \mathrm{a}, 68 \mathrm{~b}, 69,70,71,72,73,81,82,83,84$, $87,89,90)$.

\section{RESULTS}

\section{HPV genotypes in LSIL}

HPV genotypes found in LSIL were HPV 6, HPV 16, HPV 18, HPV 33, HPV 52, HPV 68, and HPV 72 (Table 1). Single infection with low-risk HPV, low-risk HPV infections combined, and the combined high-risk HPV infection in LSIL were not found in this study. A single infection of high-risk HPV 16, HPV 18, HPV 52, coinfection low-risk HPV 6 and high-risk HPV 18, lowrisk HPV 6 and high-risk HPV 33, low-risk HPV 72 and high-risk HPV 68 were identified in this study (Table $1)$.

\section{HPV genotypes in HSIL}

HSIL HPV genotypes were HPV 6, HPV 16, HPV 18, HPV 26, HPV 31, HPV 45, HPV 59, and HPV 61 (Table 1). Single infection low-risk HPV and low-risk HPV coinfection in HSIL were not found in this study. A single infection of high-risk HPV 16, HPV 18, HPV 59 , HPV infection of the combined high-risk HPV 26 and 61, high-risk HPV 16 and HPV 31 infection with HPV 6 combination of low-risk and high-risk HPV 45 were identified in this study.

\section{HPV genotypes in precancerous lesions}

Variants of HPV genotypes in precancerous lesions were HPV 6, HPV 16, HPV 18, HPV 26, HPV 31, HPV 33, HPV 45, HPV 52, HPV 59, HPV 68, and HPV-72
(Table 1). Single infection of low-risk HPV and lowrisk HPV coinfection were not found in precancerous lesions in this study. A single infection of high-risk HPV, high-risk HPV 16, HPV 18, HPV 52, HPV 59, coinfection of high-risk HPV 26 and HPV 61, high-risk HPV 16 and HPV 31 infection combined low-risk HPV 6 and high-risk HPV 33, low-risk HPV 6 and high-risk HPV 18, low-risk high-risk HPV 6 and HPV 45, lowrisk HPV 72 and high-risk HPV 68 were found in this study (Table 1).

\section{DISCUSSION}

HPV genotype variant in LSIL

HPV 16, HPV 35, HPV 18, HPV 52 and HPV 53 are the top five HPV genotypes in Africa (Ogembo et al 2015). HPV 16, HPV 31, HPV 52, HPV 59 and HPV 18 are the top five HPV genotypes in Europe (Monia et al 2016). Cosette et al (2016) in their study obtained top five genotypes in LSIL which were HPV 16, HPV 82, HPV 26, HPV 31 and HPV 58 in America. Zulqarnain et al (2015) in their study found five genotypes in Asia which were HPV 16, HPV 52, HPV 33, HPV 54, and HPV 11. Tobing et al (2014) found the top five in Bandung which were HPV 16, HPV 18, HPV 45, HPV 52, and HPV 51. Schellekens (2004) also found the top five in Jakarta which were HPV 16, HPV 18, HPV 52, HPV 45, and HPV 33. This study obtained different variants of LSIL HPV genotypes in Dr. Soetomo Hospital, Surabaya which were HPV 16, HPV 18, HPV 6, HPV 52, and HPV 33 (Table 1).

Table 1. Variant of genotypes in precancerous lesions of cervical tissue

\begin{tabular}{lcccc}
\hline The Degree of Lesion & Single Infection & Amount (\%) & Coinfection & Amount (\%) \\
\hline LSIL & HR HPV 16 & $8(53.33 \%)$ & LR HPV 6 + HR HPV 31 & $1(6.67 \%)$ \\
$(\mathrm{n}=15)$ & HR HPV 18 & $3(20 \%)$ & LR HPV 6 + HR HPV 18 & $1(6.67 \%)$ \\
& HR HPV 52 & $1(6.67 \%)$ & LR HPV 72 + HR HPV 68 & $1(6.67 \%)$ \\
HSIL & & & & \\
$(\mathrm{n}=10)$ & HR HPV 16 & $4(40 \%)$ & LR HPV 6 + HR HPV 45 & $1(10 \%)$ \\
& HR HPV 18 & $2(20 \%)$ & LR HPV 61 + HR HPV 26 & $1(10 \%)$ \\
& HR HPV 59 & $1(10 \%)$ & HR HPV 16 + HR HPV 31 & $1(10 \%)$ \\
Precancerous lesions & & & & \\
$(\mathrm{n}=25)$ & HR HPV 16 & $12(48 \%)$ & LR HPV 6 + HR HPV 31 & $1(4 \%)$ \\
& HR HPV 18 & $5(20 \%)$ & LR HPV 6 + HR HPV 18 & $1(4 \%)$ \\
& HR HPV 52 & $1(4 \%)$ & LR HPV 6 + HR HPV 45 & $1(4 \%)$ \\
& HR HPV 59 & $1(4 \%)$ & LR HPV 61 + HR HPV 26 & $1(4 \%)$ \\
& & & LR HPV 72 + HR HPV 68 & $1(4 \%)$ \\
& & & HR HPV 16 + HR HPV 31 & $1(4 \%)$ \\
\hline
\end{tabular}




\section{HPV genotype variant in HSIL}

Ogembo et al (2015) in their study found HPV 16, HPV 18, HPV 35, HPV 52 and HPV 58 in Africa. Pablo et al (2009) in their study found the top five genotypes in Europe which were HPV 16, HPV 53, HPV 58, HPV 6 and HPV 66. Cosette et al (2016) found five genotypes of HPV in HSIL in their study in the United States which were HPV 81, HPV 16, HPV 26, HPV 31 and HPV 33. Zulqarnain et al (2015) obtained HPV genotypes in Asia which were HPV 16, HPV 52, HPV 33, HPV 54, and HPV 11. A study in Bandung by Sahiratmadja (2014) found five genotype HPV 16, HPV 18, HPV 45, HPV 52, and HPV 35. Smith et al (2007) found five genotypes of HPV in HSIL in Jakarta, namely HPV 16, HPV 52, HPV 35, HPV 33, and HPV 31 . The researchers found variants of different genotypes by previous researchers, five genotypes of HPV in HSIL in Dr. Soetomo Hospital were HPV 16, HPV 18, HPV 59, HPV 45, and HPV 31 (Table 1).

\section{Genotipe variant in precancerous lesions}

This study obtained HPV 6 in the age group of 34-51 years, HPV 16 in the age group of 34-51 years and 5863 years, HPV 59 in the age group of 52-57 years, HPV 31 in the age group of 58-63 years, and HPV 52 in the age group of 40-45 years. Based on these data, there were similarities with Monia et al's (2016) study which found HPV 6 and HPV 40 in the age group <30 years, $31-40$ years, $41-50$ years and $>50$ years. HPV 16 and HPV 59 were found in the age group 31-40 years and $>50$ years. HPV 31 and HPV 52 were found in the age group <30 years, $31-40$ years and $>50$ years. HPV 16 was found in the age group of 34-51 years for sexually active women $<30$ years, while HPV infection develops into pre-cancerous lesions in 5-7 years (Monia et al 2016). HPV 16 was also found in the age group of 5863 years because at this age, the body's immunity undergoes degenerative progression of precancerous lesions and high cervical tissue.

HPV infection causes precancerous lesions originated from the bond between HPV L1 receptor of GFR HSPGs which forms complex HSPGs/GF. HPV L1 complex bonds with HSPGs/GF stabilized by TEMS and causes the decline of primary, HSPGs and GFR receptor affinity. CYB interacts with a6ß4 integrin receptor binding resulting in an increase in HPV L2 A2 $\mathrm{N}$ terminus exposure, while the structure of HPV L1 pentamer is converted into altered HPV L1. HPV VLP conformational changes lead to modulation of EGFR resulting in the initiation of signaling cascade and activate the PI3K pathway. The activation of the PI3K pathway results in downstream signaling infection. Actin filaments mediates transport of retrograde flow cell. HPV enters into intra-cell and intracts with the host cell of HPV VLP. E6 oncoprotein degrades p53 and activates E2F. E2F activation results in increased C-myc and N-myc, while the E7 oncoprotein that degrades PRB CDK P21 decreases and increases. It becomes uncontrolled cell proliferation and leads to precancerous lesions of cervical tissue (Morshed et al 2014).

Ogembo et al (2015) in their study found HPV 16, HPV 18, HPV 35, HPV 52 and HPV 58 which were five HPV genotypes in precancerous lesions in Africa. Cosette et al (2016) found top five HPV genotypes in their study in the United States which were HPV 81, HPV 16, HPV 26, HPV 31 and HPV 33. HPV 16, HPV 31, HPV 52, HPV 59 and HPV 18 were top five HPV genotypes in Europe (Monia et al 2016). Zulqarnain et al (2015) in their study found top five HPV genotypes in Asia, which were HPV 16, HPV 52, HPV 33, HPV 54, and HPV 11. Tobing et al (2014) found top five HPV genotypes, which were HPV 16, HPV 18, HPV 45, HPV 52, and HPV 51. Schellekens (2004) also found top five HPV genotypes in Jakarta, which were HPV 16, HPV 18, HPV 52, HPV 45, and HPV 33. This study found top five in precancerous lesions of HPV genotypes, which were HPV 16, HPV 18, HPV 6, HPV 59 and HPV 45 (Table 1).

A single infection of high-risk HPV 16 dominant in precancerous lesions, both LSIL and HSIL (Table 1) for high-risk HPV 16 has high affinity to receptors on the surface of epithelial cells of the cervix than other HPV genotypes. Integrin receptors of a6ß4 and HSPG on the surface of epithelial cells of the cervix play an important role as the site of HPV VLPs bonding with virus-host cell interaction.

HPV 16 is dominant, either single or multiple infection in precancerous lesions. Cosette et al (2016) revealed the high-risk HPV 16 was more frequent to cause precancerous cervical rather than other high-risk HPV genotypes. HPV 16 globally causes one half of cervical cancer cases. The assessment of HPV 16 carcinogenicity was very difficult. The determination of precancerous and cancerous disease when combined with HPV infection resulted in HPV 16 as one of the most common HPV found.

A study conducted by Zulqarnain et al (2015) also found that HPV infection was commonly caused by single high-risk HPV 16, while HPV 11 and HPV 54 dominated in single low-risk HPV infection group. The combined high-risk HPV infection, joint infection of low-risk HPV and combined infections of low-risk HPV and high-risk HPV were also found. Researchers found that a single infection of high-risk HPV 16 was ranked the top, but not found a single infection with low-risk 
HPV or low-risk HPV infection, but they found combined joint infection of low-risk HPV and high-risk HPV, as well as combined high-risk HPV infection. Zulqarnain et al (2015) also showed that high-risk HPV prevalence was significantly higher than that in low-risk HPV which is in line with the results of this study (Table 1). Based on these findings, it can be concluded that the global prevalence of high-risk HPV was significantly higher than in low-risk HPV in precancerous lesions.

This study obtained the same genotype variants with Zulqarnain et al (2015), which were a single infection of high-risk HPV 16, HPV 18, HPV 52, HPV 59, and infection of high-risk HPV 16 and HPV 31 combination. This study also found a new variant that has not been found in previous studies, which were the combinations of low-risk HPV 6 and high-risk HPV 33 infections, low-risk HPV 6 and high-risk HPV 18, lowrisk HPV 6 and high-risk HPV 45, low-risk HPV 72 and high-risk HPV 68, and infections of the combined highrisk HPV 26 and HPV 61 (Table 1). The differences in the HPV prevalence can occur due to differences in sample populations and method use, in accordance with the statement of Monia et al (2016) which stated that HPV infection varies by geographical region, age, life style and social economic status.

HPV 16 is dominant, either in single or multiple infections in precancerous lesions in this study (Table 1). Tobing et al (2014) claimed that the combined genotype HPV infection was predominantly found in patients with cervical cancer. All patients were predominantly infected with high-risk HPV 16 (90\%) and one patient infected with low-risk HPV even when there was an infection combined with a high-risk HPV 16, and there was no difference in patients' life with a single infection (33-64 years) than patients with coinfection (34-70 years). It is in line with the results of this study (Table 1). Based on these findings, all age groups were susceptible to single or joint infections of low-risk and highrisk HPV genotypes.

HPV 6 ranked second after HPV 16 in this study. It was suggested that genotypes of HPV 6 and HPV 11 cause genital wart and can infect the genital mucosa. The results showed that there was one case $(10 \%)$ of HPV 6 on HSIL. HPV 6 did not only infect in precancerous lesions. Joint infection of low-risk HPV 6 and high-risk HPV 33, low-risk high-risk HPV 6 and HPV 18 were found in LSIL. Coinfection of low-risk HPV 6 and highrisk HPV 45 was found in HSIL. HPV 6 can cause HSIL because there is infection combination with highrisk HPV 33, HPV 18, and HPV 45. The determination of precancerous and cancerous risks when combined with HPV infection resulted in HPV 16 which was a high-risk HPV genotype (Cosette et al 2016).

\section{CONCLUSION}

The HPV genotypes found in LSIL cervical tissue in Dr. Soetomo Hospital, Surabaya were HPV 16 (8/15), HPV 18 (3/15), HPV 52 (1/15), HPV 6+31 (1/15), HPV 6+18 (1/15), HPV 72+68 (1/15). The HPV genotypes found in HSIL cervical tissue in Dr. Soetomo Hospital, Surabaya were HPV 16 (4/10), HPV 18 (2/10), HPV 59 (1/10), HPV 6+45 (1/10), HPV 61+26 (1/10), HPV 16+31 (1/10). The prevalence of HPV in cervical precancerous lesions is a single infection by HPV 16 (48\%), HPV 18 (20\%), HPV 52 (4\%), HPV 59 (4\%), and multiple infection by HPV $6+31$, HPV $6+18$, HPV $6+45$, HPV $16+31$, HPV $61+26$, HPV $72+68$ was $4 \%$. As a suggestion, the prevalence of HPV genotypes from cervical precancerous lesion in other district hospital in Indonesia should be investigated.

\section{REFERENCES}

Cosette MW, Wiliam CH, Mark S, Philip E. C., 2016. human papillomavirus genotypes and the cumulative 2-years risk of cervical precancer. Division of Cancer Epidemiology and Genetic and National Cancer Institute, 1-8

Ministry of Health (2014). Hospital Information System

Monia A, Emna E, Hajar L, et al (2016). Prevalence genotype distribution and risk factors for cervical human papillomavirus infection in the Grand Tunis Region, Tunisia. PloS One Journal 11, 1-12

Markowitz LE, Liu G, Hariri S, Steinau M, Dunne EF, Unger ER (2016). Prevalence of HPV after introduction of the vaccination program in the United States. Pediatrics 137, e20151968. doi: 10.1542/ peds.2015-1968

Morshed K, Gruszka DP, Szymanski M, Dacewicz MP (2014). Human papillomavirus (HPV) - structure, epidemiologi, dan pathogenesis. Elsevier Urban \& Partner Sp. z o.o., 213-220

Ogembo RK, Philimon NG, Alaina JS, et al (2015). Prevalence of human papillomavirus genotypes among African women with normal cervical cytology and neoplasia: a systematic review and meta-analysis. Plos One 10, 1-16

Pablo CZ, Sebastian OR, Joaquin MB, et al (2009). Genotype distribution of human papillomavirus (HPV) and co-infection in cervical cytologic specimens from two outpatient gynecological clinics in a region of South East Spain. BMC Infectious Diseases, 1-6

Rahmawati A, Damayanti, P CRS, Lumintang H (2014). Correlation of expression P16 on genital wart with 
various degress of cervical dysplasia. BIKKK Berkala Ilmu Kesehatan Kulit dan Kelamin Periodical of Dermatology and Venereology 26, 183189

Sahiratmadja E (2014). Multiple human papilloma virus infections predominant in squamous cell cervical carcinoma in Bandung 33, 33-43

Schellekens MC (2004). Prevalence of single and multiple HPV types in cervical carcinomas in Jakarta, Indonesia. Gynecologic Oncology 93, 49-53

Sherris J, Wittet S, Kleine A, et al (2009). Evidencebased, alternative cervical cancer screening approaches in low-resource settings. International Journal of Gynecology \& Obstetrics 35, 147-151

Smith JS, Lisa L, Broke H, et al (2007). Human papillomavirus type distribution in invasive cervical cancer and high-grade cervical lesions: a meta-analysis update. International Journal of Cancer 121, 621-632
Stanley M, Lowy DR, Frazer I (2006). Chapter 12: prophylactic HPV vaccines: underlying mechanisms. Vaccine 24, 106-13

Tobing MD, Sahiratmadja E, Dinda M, Hernowo BS, Susanto H (2014). Human papillomavirus genotypes profile in cervical cancer patients at Dr. Hasan Sadikin General Hospital, Bandung, Indonesia. Asian Pac J Cancer Prev 15, 5781-5

Vet JNI, de Boer MA, van den Akker BEWM, et al (2008). Prevalence of human papillomavirus in Indonesia: a population-based study in three regions. $\mathrm{Br} \mathrm{J}$ Cancer 99, 214-218

WHO, 2014. Comprehensive Cervical Cancer Control. Geneva, 58-64 and 366-378

Zulqarnain B, Lei Y, Tao Y, et al (2015). Status of human papillomavirus infection in the ethnic population in Yunnan Provience China. Biomed Research International, 1-8 